Research note

\title{
Sensitivity of the nested-polymerase chain reaction (PCR) assay for Brugia malayi and significance of 'free' DNA in PCR-based assays
}

\author{
Janet Cox-Singh $^{\mathrm{a}, *}$, Andrea S. Pomrehn ${ }^{\mathrm{b}}$, Nathan D. Wolfe ${ }^{\mathrm{c}}$, Hasan A. Rahman ${ }^{\mathrm{d}}$, \\ Huong-Ying $\mathrm{Lu}^{\mathrm{a}}$, Balbir Singh ${ }^{\mathrm{a}}$ \\ ${ }^{a}$ Faculty of Medicine and Health Sciences, University Malaysia Sarawak, 94300 Kota Samarahan, Sarawak, Malaysia \\ ${ }^{\mathrm{b}}$ Department of Developmental Biology, Beckman Center, Stanford University School of Medicine, Stanford, CA 94035, USA \\ ${ }^{\mathrm{c}}$ Emerging Infections in Cameroon Project (EICAM), Johns Hopkins School of Hygiene and Public Health, 624N Broadway, Baltimore, MD 21205, USA \\ ${ }^{\mathrm{d}}$ Ministry of Health Malaysia, Bukit Damansara, Jalan Dungun, 50490 Kuala Lumpur, Malaysia
}

Received 7 August 2000; received in revised form 14 August 2000; accepted 14 August 2000

\begin{abstract}
The blood filtration method was used as the gold standard to determine the detection level of simple blood-spot sampling and nestedpolymerase chain reaction (PCR) for Brugia malayi. Of 100 samples, 48 were filtration-positive. Of these, 26 had microfilaria counts that were low enough ( $<1-29$ microfilariae/ml) to accurately assess the limit of detection by nested-PCR. Nested-PCR consistently detected $B$. malayi DNA in samples with $\geq 10$ microfilariae/ml. Post-filtration, microfilaria-depleted, blood-spots from microfilaria-positive samples were screened by nested-PCR and B. malayi specific 'free' DNA was detected in $51.7 \%$ of these samples. There was no evidence for 'free' DNA in microfilaria-negative individuals from this endemic community. (C) 2000 Published by Elsevier Science Ltd. on behalf of the Australian Society for Parasitology.
\end{abstract}

Keywords: Brugia malayi; Nested-polymerase chain reaction; Sensitivity; Free DNA; Filtration

Brugia malayi is one of the causative organisms of lymphatic filariasis and is restricted to the Asian region [1]. Recently we described a simple blood-spot sampling method coupled with nested-polymerase chain reaction (PCR) to detect circulating B. malayi microfilariae in individuals living in remote endemic areas [2]. The assay was tested on 145 field samples and was positive for all 30 microscopy-positive samples. Additionally, 13 microscopy-negative samples tested positive by the blood-spot assay, potentially indicating that the nested-PCR assay was more sensitive than microscopy. Here we report a study designed to determine the detection level of the nested-PCR assay using the blood filtration assay as the gold standard.

Previous studies on PCR methods for B. malayi have suggested that some infected individuals have circulating B. malayi DNA in the blood in the absence of circulating microfilariae [3,4]. The presence of 'free' DNA, if confirmed in our population, would theoretically overcome the problem of night sampling to coincide with the nocturnal microfilaria shedding characteristic of $B$. malayi infection

\footnotetext{
* Corresponding author. Tel.: +60-82-671-000; fax: +60-82-671-975.

E-mail address: cox@tm.net.my (J. Cox-Singh).
}

[5]. PCR analysis of the collected samples both before and after filtration in this study were tested for the presence of 'free' DNA in individuals with circulating microfilariae.

The filtration concentration method for microfilaria enumeration per $\mathrm{ml}$ of blood was used as the reference for accurate determination of microfilaria density [6]. For this method 1.5-10.0 (mean $4.1 \mathrm{ml}$ ) of venous blood, from 100 consenting individuals living in a remote $B$. malayi endemic area of Sabah, were collected into sodium citrate. The blood samples were collected in conjunction with a routine $B$. malayi screening exercise conducted by officers of the Vector-Borne Diseases Control Program, Sabah. Sample collection was complicated by the need to include a proportion of individuals with microfilaria counts below the level of detection by Giemsa-stained thick blood films. Studies have shown familial clustering of infected individuals and, by collecting samples from individuals who were microfilaria-negative by microscopy but residing with microfilariapositive family members, we were able to collect blood samples with microfilaria levels below the detection level of microscopy [7]. Of the 100 specimens collected from family members, 26 samples met this criterion. All of the samples collected $(n=100)$ were included in the study to determine the detection level of the nested-PCR method. 